\title{
Financial Markets between Efficiency and Persistence: Empirical Evidence on Daily Data
}

\author{
Flifel Kaouther, $\mathrm{PhD}$ \\ Contractual teacher in finance, money and banks, Institute of Higher Commercial Studies \\ IHEC Carthage Présidence-2016 Tunis, Tunisia \\ Tel: 216-22-80-2093Ｅ-mail: flifelkaouther@yahoo.fr
}

Received: May 21, 2012 Accepted: December 15, 2012 Published: December 17, 2012

doi:10.5296/ajfa.v4i2.1827 URL: http://dx.doi.org/10.5296/ajfa.v4i2.1827

\begin{abstract}
:
Today, the assumption of efficient capital markets is very controversial, especially in these times of crisis, and is challenged by research showing that the pricing was distorted by detection of long memory. This study aims to test the existence of the persistence effect using statistical analysis such as R/S, its corollary named Hurst exponent and the ARFIMA process. In practical terms, our research was conducted on daily data on stock returns of 21 countries classified into three groups according to their levels of development over the period from January 2000 to December 2010. The results obtained allowed us to conclude that the property of of long rang dependence tend to be associated with relatively thin stocks
\end{abstract}

Keywords: Efficiency, Long memory, Analysis R / S, Hurst exponent, ARFIMA model 


\section{Introduction}

Validated by thousands empirical testing on all financial markets in the world, the theory of efficient capital markets requires that a market is efficient when all relevant information to assess the securities traded on the market at any time is reflected in the price of securities.

According to the theory of efficiency, financial markets incorporate the consequences of past events and accurately reflect the expectations expressed about future events. All known or anticipated events are integrated into existing courses, and it would be uselless to try to predict using some mathematical model.

We can say that markets are efficient when investors with inside information or a monopoly on certain information are unable to influence the price of securities, which will be true as long as the market authorities can prevent and suppress insider trading.

In the speculation theory of Bachelier ${ }^{1}$, the differences between $\mathrm{P}_{\mathrm{t}}$ and $\mathrm{P}_{\mathrm{t}-1}$ noted $\varepsilon \mathrm{t}$ are:

- Unpredictable before the implementation of the event.

- Independent, since no one can use the past to make future profits.

- Having a normal distribution, that is to say that the distribution of deviations follows a normal Gaussian law. There is no excessive deviation from the mean. The deviation returns to the normal one.

These characteristics refer empirically to uncorrelated price series. Stock market fluctuations are normal and without memory. This means that the action of arbitrageurs is effective, the existence of small or low autocorrelation in the series of prices is rapidly disappearing because rational agents, called in the jargon of Fama, knowledgeable professionals, end by driving prices to their equilibrium: "Mean reverting behavior". The market is efficient, well refereed and corresponds to the theory of random walk and martingale.

However, an imperfect market may have a memory effect. Empirically, the series of prices can be more or less correlated. Low autocorrelations mean a short memory. In this case, the price quickly regains its equilibrium value. Conversely, high autocorrelations reflect a long memory $^{2}$ this means that the price slowly integrates information on the fundamentals, impacts on profits, interest rates....Long memory reflects lasting deviations between the prices and the fundamental value. These differences persist and cannot be reduced in the long term when the price returns to the standard equilibrium.

In general the hypothesis of efficiency implies that the return series are characterized by a zero memory (total independence of returns) which means the absence of serial correlation between them and therefore we cannot predict future returns to from past returns. The controversy about

\footnotetext{
${ }^{1}$ In his thesis entitled Theory of speculation, backed March 29, 1900, he introduced the use of the Brownian movement in finance (discovered by Brown, a biologist), which is the basis of most pricing models in finance, including the Black-Scholes (1973).

2 The phenomenon of long memory is also known as Joseph effect. (Mandelbrot and Wallis 1968). It refers to a passage in the Bible where Joseph interprets Pharaoh's dream: he saw seven lean cows seven large monitor and Joseph concludes that this was a planned series of seven-year drought to seven years good harvest (Mignon (1998), p.191). This means that the periods when the series is above (or below) its mean are extremely long. The presence of long memory in time series, refers to lasting consequences but not a permanent shock to the said series.
} 
this is that the proponents of efficiency seem to accept the predictability of short-term profitability (low dependence where dependence between observations of short-term) but simultaneously advocate the absence of long memory in these same series.

Thus, the ability to predict future performance from past one is observed to be a crucial issue in finance, both from an academic or practical point of view.

Several statistical tools for the development of chaos theory on economic and financial data were used. Indeed, the study of Hsieh (1991) in the U.S. market raises many doubts about the fact that the S\& P500 can be considered following a random walk, the same way Peters (1994) highlights the dependencies long-term returns of the Dow Jones Industrial. Opong, Mulholland, Fox and Farahmand (1999) studied the returns of major market indices of England, and Jacobsen (1996) studied the long-term dependencies indices of seven industrialized countries. Finally, Golaka and Nath (2001) attempted to test the presence of long memory in the Indian market using daily NIFTY indices.

The objective of the paper is to test stock index returns for long memory using data from a sample of 21 stock markets with a wider development spectrum in terms of size, liquidity and importance in the economy, as an attempt to provide further international evidence on the link between long memory in stock returns and the level of stock market development. While the sample includes the developed stock markets of USA, the France, the Germany the Italy, the UK, the Japan, and the USA, it also includes, in addition to the emerging markets of Tunisia, South Africa, Egypt, Saudi Arabia, South Korea, Argentina, Australia, those of the seven emerging powers of Turkey, Indonesia, Brazil, Mexico, China, India and Russia .

In what follows we will expose, first, a literature review of researches made on the concept of long memory, we will then set out, in the second section, the concept of Hurst exponent, the $\mathrm{R} / \mathrm{S}$ and the ARFIMA model, then we will show the empirical evidence. Finally, we will present the results.

\section{Literature Review}

The phenomenon of long memory appeared in the year 1895 from observations of the astronomer Newcomb and the chemist Student. The fact that time series may exhibit a dependence structure of long-term became important research topic in economics. Hurst (1951, 1957), Mandelbrot and Wallis (1968), Mandelbrot (1972) and McLeod and Hipel (1978), the search for dependence structures in long-term economic and financial series has been the subject of many contributions. Among these studies may be mentioned those of Diebold and Rudebusch (1989) and Sowell (1992) on the real product, Diebold and Rudebusch (1991) on consumption, Shea (1991) and Backus and Zin (1993) on the term structure interest rates or LO (1991) on the stock market.

The interest in research on long memory is further highlighted by recent developments back from modeling the volatility of the series through ARFIMA process, leading to the process FIGARCH (fractionally see Bollerslev and Mikkelsen (1996) integrated GARCH). Despite the development of these various research studies of the forecast series through ARFIMA processes, they are relatively rare in the literature. Baillie (1996), Doukhan et al. (2003) and 


\section{Macrothink}

Asian Journal of Finance \& Accounting

ISSN 1946-052X

2012, Vol. 4, No. 2

Robinson $(1994,2003)$ provide an overview of the processes of long memory and fractional integration.

Davidson and Terasvirta (2002), in turn, they studied the non-stationary, long memory and nonlinearity of time series. Since then, this concept has been applied in various fields, including for example: finance on a series of inflation rates (Baillie et al (1996)), on a series of exchange rates (Ferrara and Guégan (2001)) and price series of shares traded in stock markets (Willinger et al (1999)).

Timotej Jagric, Boris Podobnik, Marko Kolanovic (2005) in their paper, presents a wavelet analysis of long-range dependence (LRD) based on the Hurst exponent. An estimator is used to perform an analysis of LRD in the capital markets of six transition economies. The results suggest that we can divide the stock markets into two groups: markets with strong LRD (the Czech Republic, Hungary, Russia, and Slovenia), and markets with no or only a weak form of LRD (Poland and Slovakia). Additionally, if the Hurst exponent is estimated on a sliding time window, the results show some additional properties, which we believe are representative for the markets in transition economies.

David, McMillan, Pako and Thupayagale, (2009) in their article they funds some results showing that African markets (largely) display a predictable component in returns; while evidence of long memory in volatility is very mixed. In comparison, results from the control of the UK and USA show short memory in returns while evidence of long memory in volatility is mixed. These results show that the behavior of equity market returns and risks are dissimilar across markets and this may have implications for portfolio diversification and risk management strategies.

We propose to continue the work on long memory with a study of the dynamics of stock indices through modeling ARFIMA (Auto Regressive Fractionally Integrated Moving Average) and the work of Timotej Jagric, Boris Podobnik and Marko Kolanovic (2005) and David G. McMillan, Pako Thupayagale, (2009) by expanding the sample by the choice of 21 country indices classified into three groups according to their levels of development over the period from January 2000 to December 2010. Such a model aims to reflect the phenomena present in long memory time series.

\section{Methodology}

To detect the dependence of long-term or the presence of long memory phenomenon, Mandelbrot suggests using the statistic R/S also called (rescaled Range or Range over standard deviation) that was originally developed by Hurst (1951) at its analysis on the Nile floods.

\section{a- Hurst exponent}

The invention of Hurst is the study of long-term statistical dependence on various hydrological series. This is from his study of the ideal capacity of a water tank that Hurst could exhibit the long memory process. The empirical law of Hurst is by dividing the tank capacity by the standard deviation of $\mathrm{T}$ successive discharges of a river; Hurst found that this 
ratio is proportional to $\mathrm{T}^{\mathrm{H}}$, where $\mathrm{H}$ is a constant called Hurst exponent usually between 0 and 1. If water levels were independent of the river, Hurst should have found that this ratio behaved as $\mathrm{T}^{1 / 2}$. The fact that the ratio of the capacity of the standard deviation is proportional to $\mathrm{T}^{\mathrm{H}}$ is known as the "law of Hurst" or " $\mathrm{T}^{\mathrm{H}}$ Law".

\section{b- Rescaled range statistic}

The statistical $\mathrm{R} / \mathrm{S}$ is defined as the range $\mathrm{R}$ of the partial sums of deviations of a time series from its mean divided by its standard deviation $\left(\mathrm{S}_{\mathrm{t}}\right)$. Thus, a time series $\mathrm{X}_{\mathrm{t}}, \mathrm{t}=1 \ldots \ldots \mathrm{T}, \mathrm{X}_{\mathrm{T}}$ is the average; the statistical $\mathrm{R} / \mathrm{S}$ denoted by $\mathrm{Q}_{\mathrm{T}}$ is written:

$$
\mathrm{Q}_{\mathrm{T}}=\frac{\mathrm{R}}{\mathrm{S}_{\mathrm{T}}}=\frac{\max _{1 \leq \mathrm{k} \leq \mathrm{T}} \sum_{\mathrm{j}=1}^{\mathrm{k}}\left(\mathrm{X}_{\mathrm{j}}-\overline{\mathrm{X}}_{\mathrm{T}}\right)-\min _{1 \leq \mathrm{k} \leq \mathrm{T}} \sum_{\mathrm{j}=1}^{\mathrm{k}}\left(\mathrm{X}_{\mathrm{j}}-\overline{\mathrm{X}}_{\mathrm{T}}\right)}{\left[\frac{1}{\mathrm{~T}} \sum_{\mathrm{i}=1}^{\mathrm{T}}\left(\mathrm{X}_{\mathrm{j}}-\overline{\mathrm{X}}_{\mathrm{T}}\right)^{2}\right]^{1 / 2}}
$$

With R: the extent

$\mathrm{S}_{\mathrm{T}}$ : the standard deviation of the series.

The range $\mathrm{R}$ is always positive. Therefore, the statistic $\mathrm{R} / \mathrm{S}$ is always non-negative. In his study, Hurst found that the statistic $\mathrm{R} / \mathrm{S}$ behaves like $\mathrm{T}^{\mathrm{H}}$, where $\mathrm{H}$ is a mean of 0.73 . The constant $\mathrm{H}$ is called Hurst exponent $(0<\mathrm{H}<1)$ which is given by:

$$
\mathrm{H} \sim \frac{\log \mathrm{Q}_{\mathrm{T}}}{\log \mathrm{T}}
$$

The Hurst exponent $\mathrm{H}$ is defined as $\mathrm{H} \sim \frac{\log Q_{T}}{\log T}$ is particularly interesting insofar as the value used to classify time series according to their dependence structure.

$\mathrm{R} / \mathrm{S} \sim \mathrm{T}^{\mathrm{H}}$

Hurst's law can be apprehended through $\mathrm{R} / \mathrm{S}$ which is asymptotically proportional to $\mathrm{T}^{\mathrm{H}}$ with 0 $<\mathrm{H}<1$.

In his article in 1997, Mignon has determined a correlation measure of long-term CH linked to the Hurst exponent.

$\mathrm{C}^{\mathrm{H}}=2^{2 \mathrm{H}-1}-1$

$\mathrm{C}^{\mathrm{H}}$ is a measure of long-term correlation between past observations and future observations for a past and a future sufficient long $\mathrm{C}^{\mathrm{H}}>0$ if $\mathrm{H}>1 / 2$ When $\mathrm{H} \sim 1, \mathrm{C}^{\mathrm{H}}$ then increases. We can specify three types of dependencies based on the values of $\mathrm{H}$ and $\mathrm{C}^{\mathrm{H}}$.

- If $\mathrm{H}=1 / 2$ then $\mathrm{C}^{\mathrm{H}}=0$, therefore the process has no dependence on long-term, this type of process is called short memory.

- If $1 / 2<\mathrm{H}<1$, the autocorrelations are positive and decrease very rapidly when the delay increases, these are the characteristics of a long memory process, we can say here that the series thus has the effect of dependence of Joseph long term. This is called persistence 


\section{Macrothink}

phenomenon in case "if the series has been on the rise the previous period, there is a high probability that it is also on the rise next period."

- If $0<\mathrm{H}<1 / 2$, we are talking about anti-persistent process that is to say that the $\mathrm{C}^{\mathrm{H}}$ correlation is negative this is explained by rising phases which tend to be followed by phases of decline. This is a particular form of long memory, which was named "anti-persistence of long-term dependency."

Therefore, the Hurst exponent, which is determined from analysis of the R/S provides a measure of the intensity of long-term dependence in a time series. But the major drawback is that the statistic R/S does not determine whether $(H)$ is statistically significant, it is for this reason that Lo (1991) developed the modified R/S statistic.

\section{c- Lo's modified rescaled range statistic (1991)}

The statistical R/S (rescaled range) introduced by Hurst in 1951 has a major drawback is that it is very sensitive to the dependence of short-term and also it is not a statistical test since its theoretical distribution is unknown.

As a solution to these problems, Lo (1991) developed the modified R/S statistic from where it tests the null hypothesis of short memory against the alternative of long memory.

The modified $\mathrm{R} / \mathrm{S}$, denoted $\mathrm{Q}_{\mathrm{mT}}$ is written:

$$
\begin{aligned}
Q_{m T} & =\frac{R}{S_{T}(q)}=\frac{1}{S_{T}(q)}\left[\max _{1 \leq k \leq T} \sum_{j=1}^{k}\left(X_{j}-\bar{X}_{T}\right)-\min _{1 \leq k \leq T} \sum_{j=1}^{k}\left(X_{j}-\bar{X}_{T}\right)\right] \\
S_{T}^{2}(q) & =\frac{1}{T} \sum_{j=1}^{k}\left(X_{j}-\bar{X}_{T}\right)+\frac{2}{T} \sum_{j=1}^{k} \omega_{j}(q)\left[\sum_{i=j+1}^{k}\left(X_{j}-\bar{X}_{T}\right)\left(X_{i-j}-\bar{X}_{T}\right)\right]
\end{aligned}
$$

The weights $w_{j}(q)$ have been suggested by Newey and West (1987).

The modified R/S statistic differs from the R/S only by its traditional denominator since it includes not only the standard deviation of the series but also the weighted autocovariances.

Concerning the choice of q, Andrews (1991)) provides the following rule:

$$
\mathrm{q}=\left[\mathrm{K}_{\mathrm{T}}\right] \text { ou } \mathrm{K}_{\mathrm{T}}+\left(\frac{3 \mathrm{~T}}{2}\right)\left(\frac{2 \widetilde{\varphi}}{1-\varphi^{2}}\right)^{2}
$$

with:

$\left(\mathrm{K}_{\mathrm{T}}\right)$ is the integer part of $\mathrm{K}_{\mathrm{T}}$.

$\varphi$ is the estimator of the autocorrelation coefficient of order 1.

Subsequently $\mathrm{w}_{\mathrm{j}}(\mathrm{q})$ become:

$$
\omega_{\mathrm{J}}=1-\left|\frac{\mathrm{j}}{\mathrm{K}_{\mathrm{T}}}\right|
$$


Lo (1991) defined the statistic V by $V=\frac{\widetilde{Q}}{\sqrt{T}}$ where $\widetilde{Q}$ is the modified $R / S$ statistics and $T$ the number of observations. Statistics $\mathrm{V}$ allows a test on the value of $\mathrm{H}$ by comparing the estimate with the values tabulated by Lo (1991), (Mignon (2002)).

From his article "Long-term memory in stock market pray" Lo (1991) showed a side of the robustness of the modified R/S statistics in many forms of heteroskedasticity and generally weak dependence, and on the other hand its superiority to the traditional R/S when it serves to distinguish short memory of long memory.

\section{d- The ARFIMA model}

ARFIMA models are the long memory process that identifies the phenomena of persistence. These models have been developed by Granger and Joyeux (1980) and Hosking (1981) and are a generalization of ARIMA of Box-Jenkins in which differentiation exponent of was an integer.

Recall that the ARMA (p, q) is used when the process is stationary. However, if the process is nonstationary so it must be integrated. In other words, the time series are integrated of order $\mathrm{d}$ (I (d)), therefore they should be stationary after " $d$ " differentiations in time this process is known as ARIMA (p, d, q) model where $d$ is integer.

Thus, the presence of a unit root ( $d=1$ in the ARIMA models) refers to the phenomenon of infinite memory, and no unit root $(\mathrm{d}=0)$ corresponds to the case of short memory, or even no memory. These two classical models do not take into account the intermediate cases: the existence of a parameter " $d$ " of fractional differentiation. However, the presence of such a non-integer coefficient is particularly interesting since it allows to characterize the long memory process. The ARFIMA model is a significant development in the modeling of time series, because it contains a part of an ARMA traditional side to reflect the behavior of short-term and on the other hand, a parameter of fractional integration designed to clarify the long-term movements in the series studied. Against the fractional Gaussian noise depends only on a single parameter, the Hurst exponent $\mathrm{H}$, and if he can actually characterize the behavior of a series of long-term, it cannot claim to explain the behavior in the short term.

The simplest ARFIMA process is the ARFIMA $(0, d, 0)$ or fractional noise parameter in discrete time: it is defined as follows:

$$
(1-L)^{d} X_{t}=U_{t}
$$

Hosking (1981), Geweke and Porter-Hudak (1983), Lo (1991), showed that there is a noteworthy relation between the parameter of ARFIMA processes and the Hurst exponent $\mathrm{H}$ :

$\mathrm{d}=\mathrm{H}-1 / 2$

Therefore, it is possible to perform a classification of time series based on the values of the parameter "d".

- If $0<\mathrm{d}<1 / 2$ : ARFIMA process is a stationary process with long memory. The autocorrelations are positive and decrease hyperbolically to 0 . When the delay increases, the 
spectral density is concentrated around low frequencies (slow cycles), it tends to infinity when the frequency tends to zero. We are facing a persistent process $(1 / 2<\mathrm{H}<1)$.

- If $\mathrm{d}=\mathrm{o}$, the ARFIMA process reduces to the standard ARMA process and has no structure of long-term dependency.

- If $-1 / 2<\mathrm{d}<0$, the process is anti-persistent, the autocorrelations alternate in sign and the spectral density is dominated by high-frequency components (spectral density similar to the frequency, tends to zero).

\section{Empirical Evidence}

\section{a- Database}

The collection, processing and preparation of data for empirical tests were made, largely, from daily data provided by Euronext and EMDB database. Our sample is composed by the indexes over the 21 countries ranked by their economic power (composed of 7 economic powers, 7 emerging powers and 7 other emerging powers). The study is spread over the period from January 2000 to December 2010.

\section{b- Preliminary study}

As a first step toward exploring the statistical properties of the return series and to pre-test for the presence of long memory, a battery of tests is conducted. The first set tests for the presence of unit roots in the returns series. The rejection of the unit root hypothesis is suggestive of random walk and hence of no memory in the returns series. The three unit root tests used in the paper are the Augmented Dickey-Fuller (1981), Kwiatkowski, Phillips, Schmidt and Shin. (1992), and Phillips-Perron (1988), referred to hereafter as ADF, KPSS and $P P$, respectively.

Acceptance of the assumption of stationarity, using the previous tests, does not exclude the presence of a systematic pattern or some form of dependence in the data. The presence of such properties might signal long memory. For this reason, the paper also provides the WHITE test for randomness and the BDS test, suggested by Brock et al. (1996), for a wide range of non-independence in the data such as linear and non-linear dependence and chaos.

The first three columns in table 4 provide the results pertaining to the unit root tests. As can be seen from this table, the hypothesis of unit root in stock returns is generally rejected by all three tests for all 14 markets in the sample.

\section{- The normality of returns:}

The study of the normality of returns is treated using tests that are based on coefficients of symmetry (called Skewness) noted Sk and flattening (called Kurtosis) $\mathrm{Ku}$ noted. For distributions of rates of returns that follow normal distributions, it is necessary that the distribution is symmetrical that is to say, the zero Skewness and the Kurtosis coefficient equal to 3 . 
Several tests can verify the acceptance of the normality assumption, the best known is the Jarque-Bera. He focuses on indicators measuring the shape of the distribution specially the Skewness and Kurtosis.il is based on the fact that the asymptotic distributions of these coefficients follow a standard normal distribution:

The Jarque-Bera test constructed from two independent normal variables and follows a chi-square distribution with two degrees of freedom.

If the Jarque-Bera statistic is less than the theoretical value of chi-square, the normality assumption is accepted, otherwise it is rejected. See appendix 1.

In view of the shape parameters and their significance, over the period studied in total, the kurtosis "kurtosis" is less than 3 (except for the SSE and ISE-100) for all series. This implies a high probability of extreme points and the series studied exhibit thinner tails than the normal. Moreover the coefficient of Skewness which is different from zero indicates the presence of asymmetry which contradicts the criterion of a linear Gaussian distribution, more if the coefficient is negative (SP500, FTSE JSE and MIBTEL) we say that 'there is a tail negatively skewed, in which the weight of below average returns is dominating and vice versa. Also we found that the Jarque-Bera test has a high value for all indices which confirms the non-normality of the data studied.

A normal distribution is in practice very rarely observed in financial markets. Thus, if we had applied the statistical properties of the normal distribution, the performance displayed by most active in this period of study would never have happened! The most important consequence is that this type of distribution underestimates the real risk assets. The academic world is well aware of the above, but, like the assumption of efficient markets, continues to apply the hypothesis of normal distribution by convenience.

\section{- The unit root tests}

\section{*The Dickey and Fuller}

For having a predictable random variable, it must be stationary. In order to grasp the stationary character or not of return series, we propose to apply the unit root test of Dickey-Fuller (ADF). Recall that the null hypothesis is non-stationarity of the series studied, that is to say the existence of at least one unit root. The table in Appendix 1 presents the overall results of ADF tests.

The decision rule is: If the calculated value of the t-statistic exceeds the critical value, we accept the null hypothesis of nonstationarity. If the calculated value of the t-statistic is less than the critical value, we reject the null hypothesis of nonstationarity, the conclusions to be drawn for all stock market series, the Dickey Fuller statistics are greater than the critical value this highlights the presence of a unit root and therefore the detection of non-stationary.

To confirm these results we applied the Phillips-Perron test who has the advantage of being robust to heteroscedasticity. 


\section{* Phillips Perron test (1988)}

Phillips and Perron (1988) propose a correction non-parametric of Dickey Fuller test to regulate the problem of autocorrelation and/or heteroscedastic errors. The models on which relate the Phillips Perron tests are identical to those used by Dickey Fuller. Furthermore the asymptotic distributions of Phillips-Perron test and Dickey Fuller are identical, it is sufficient to refer to tables of critical values of Dickey-Fuller. The results obtained are instructions in the table in annex 1.

In light of the results obtained, we find that the calculated value of the Phillips Perron for the index series is greater than the critical one. This comes to confirm, just for these indices, the results obtained using the Dickey Fuller test, that is to say the presence of a unit root in the series.

Beyond the tests that have attempted to provide solutions to problems raised by the application of the Dickey Fuller test other strategies have been developed, such as the KPSS test presented below.

\section{*Test-Kwiatkowski, Phillips, Schmidt and Shin (1992)}

The specificity of the KPSS test of Kwiatkowski et al (1992) is to test the null hypothesis of no unit root against the alternative hypothesis of the presence of a unit root.

The decision rule is: If the calculated value is less than the corresponding critical value, we accept the null hypothesis of stationarity. If the calculated value exceeds the corresponding critical value, we reject the null hypothesis of stationarity.

The results, reported in the tables in annex 1 indicate that the calculated values of the KPSS statistic on the index series are all higher than the critical values given; therefore we reject the null hypothesis of stationarity of the series indices.

\section{- Test of homoskedasticity, White test}

The test of homoscedasticity is useful since it allows to detect and correct errors heteroscedasticity. Several tests exist to detect heteroscedasticity as Breusch and Pagan $(1979)^{3}$ but we retain that of White. This test is based on a significant relationship between the square of the residue and one or more explanatory variables in levels and squared in a regression equation:

$$
\widehat{\varepsilon}_{t}^{2}=a_{0}+a_{1} x_{t-1}+b_{1} x_{t-1}^{2}+a_{2} x_{t-2}+b_{2} x_{t-2}^{2}+\cdots+a_{p} x_{t-p}+b_{p} x_{t-p}^{2}+v_{t}
$$

If, at least, one of the regression coefficients is significant, we reject the null hypothesis of homoscedasticity in favor of the alternative hypothesis of heteroscedasticity.

\footnotetext{
${ }^{3}$ In statistics, the Breusch-Pagan test (named after Trevor Breusch and Adrian Pagan) is used to test for heteroscedasticity in a linear regression model. It tests whether the estimated variance of the residuals from a regression are dependent on the values of the independent variables.
} 


\section{Macrothink}

If the value that emerges is to lower; (usually $\mathrm{a}=5 \%$ ) for a given level of statistical significance, we concluded that the model is homoscedastic. The results of this test are presented in table 1 of annex:

The results obtained by applying the White test confirm the heteroscedastic series since the assumption of heteroscedasticity is accepted among fifteen to twenty countries in the sample.

Note that the rejection of homoscedasticity can be due to an effect frequently encountered in financial time series which is the ARCH effect, this may indicate that profitability is not (iid) but this does not confirm the efficiency markets.

\section{- Test absence of serial correlation: Box-Pierce test}

The test is implemented for testing the presence of serial correlation in the series of stock returns, so for this test we apply to the Q statistic given by:

$$
\mathrm{BP}_{(\mathrm{q})}=\mathrm{T} \sum_{\mathrm{k}=1}^{\mathrm{q}} \hat{\delta}^{2}(\mathrm{k})
$$

Where $\mathrm{T}$ : is the number of observations of the series.

q: the number of delays.

$\varphi(\mathrm{k})$ : is the estimated autocorrelation coefficient of order K.

Statistical BP (q) follows a chi-square with (q-1) degrees of freedom under the null hypothesis of no serial correlation, the rejection of the null hypothesis implies the invalidity of the random walk model, since in this case, the returns do not follow a white noise, see annex 1 (these results are obtained for a delay equal to 36 ).

Since the series of returns having the character of heteroscedasticity is what has been detected from the White test, we decided to apply the test of box-pierce corrected for heteroscedasticity. This test is given by:

$$
\begin{gathered}
\mathrm{B}_{\mathrm{p}_{\mathrm{c}}(\mathrm{q})=[\widehat{v}(\mathrm{q})]^{-1}} \sum_{\mathrm{k}=1}^{\mathrm{q}} \xi^{2}(\mathrm{k}) \\
\hat{\mathrm{v}}(\mathrm{q})=\sum_{\mathrm{j}=1}^{\mathrm{q}} \hat{\delta}(\mathrm{j}) \\
\hat{\delta}(\mathrm{j})=\left[\frac{\sum_{\mathrm{k}=\mathrm{j}+1}^{\mathrm{T}}\left(\Delta_{\mathrm{p}_{\mathrm{k}}}\right)^{2}\left(\Delta_{\mathrm{p}_{\mathrm{k}-\mathrm{j}}}\right)^{2}}{\left[\sum_{\mathrm{k}=1}^{\mathrm{T}}\left(\Delta_{\mathrm{p}_{\mathrm{k}}}\right)^{2}\right]^{2}}\right]
\end{gathered}
$$

$P_{t}=\ln P_{t}, P_{t}$ is the price at " $t$ " 


\section{Macrothink Institute ${ }^{\mathrm{TM}}$}

The box-pierce test corrected for heteroscedasticity also follows a chi-square law with (q-1) degrees of freedom. The results of both tests are given in the table in appendix 1. In light of the results obtained, of traditional Box-Pierce test series returns exhibit autocorrelation, and therefore the assumption of random walk of stock prices is not checked.

By cons, the corrected test of Box-Pierce for heteroscedasticity indicated the absence of serial correlation; one can possibly explain this contradiction of the results obtained by the reflection of heteroscedasticity in the series. It is therefore apparent from these tests that the return series are heterospecific but has no serial correlation. We can conclude, taking into account heteroscedasticity assumption that the weak sense for this country sample is checked, and therefore the past returns, are not good predictors for future returns.

\section{- The test of the hypothesis (iid) presence of non-linear: the BDS test (1987)}

To validate the nonlinearity, we use the BDS test ${ }^{4}$ that checks almost always the nonlinearity of financial time series. Tests of non-linearity rule on the shortcomings of conventional tests of efficiency. If they show, for example, that the tests do not detect any autocorrelations dependence in the behavior of the series, showing by this that markets are efficient and perfect, it does not mean that these results are final and conclusive. Such results are only valid in a linear framework. However, the functioning of financial markets is not linear. From this perspective, a test of nonlinearity has been made by Brock, Dechert and Scheinkman (1987) says BDS test. It checks the null test of efficiency (random walk) against several alternative hypotheses including the nonlinear dependence due to market imperfections.

To characterize the nonlinear behavior of returns, Brock, Dechert, and Scheinkman (1996) proposed the BDS test, which measures the statistical significance of correlations following integrals. Defining a length e, the correlation integral is the probability that any two points are separated by a length e in the phase space.

The BDS statistic tests the null hypothesis of a series independently and identically distributed (iid) against an unspecified alternative and can be used, under certain conditions, as a test of nonlinearity. A rejection of the null hypothesis can then arise:

-Either from a dependence structure following a linear stochastic process

-Either from a non-stationarity of the series studied

-Either from a dependence structure following a nonlinear stochastic process

-Either from a dependence structure through a nonlinear deterministic process

Brock, Dechert and Scheinkman (1996) show that a satisfactory convergence is obtained when the data sets consist of at least 500 observations, however, Hsieh (1991) notes that structural changes in the data can cause a release of the null hypothesis yields. So, it is best to divide the total period into sub periods to perform separate analyzes BDS.

\footnotetext{
4 The BDS test is a portmanteau test for time based dependence in a series. It can be used fortesting against a variety of possible deviations from independence, including linear depen-dence, non-linear dependence, or chaos.
} 
A second problem with this analysis concerns the choice of the distance e to the extent that a too large value of e will tend to retain all the pairs $\left(\mathrm{X}_{\mathrm{i}}, \mathrm{X}_{\mathrm{j}}\right)$ and the values of the correlation integrals will be always equal to one, and similarly, a value too small may lead to us integrals with zero correlation, in what follows, the value of e will be set as the standard deviation of returns $\sigma$.

The test strategy is considered as new technique to study efficiency. For if, in relation to traditional tests, some variables prove linearly correlated, thus justifying the efficiency of markets, the application of this test still shows the opposite. It reveals the types of linear and nonlinear dependence. We use this test as a preliminary and important tool in the analysis of market imperfections. On reading the table in annex 2, where we took the values of $\mathrm{m}$ going from 2 to 6 , we see that the BDS statistic rejects the null hypothesis of random walk, the test values are below 1,96 .

\section{Results}

\section{a- Study of persistence over periods without considering the different trends}

As the earlier, we can estimate the Hurst exponent $\mathrm{H}$ from the application of the method $\mathrm{R} / \mathrm{S}$, and therefore we can deduce the estimate (d) from the relationship: $\widehat{d}=\widehat{H}-\frac{1}{2}$. See the second table in the appendix 2.

From the results of the table, we note that according to the method R/S, all series exhibit a phenomenon of persistence thus demonstrating the presence of long memory because the Hurst exponents are greater than $1 / 2$ and $\hat{\mathrm{d}}>0$. Nevertheless, the traditional statistic of $\mathrm{R} / \mathrm{S}$ does not determine whether the estimated value of $H$ is significantly different or not to $1 / 2$. We can work around this problem by applying the method of R/S amended, which provides us with statistical V that we compare it with the critical values given by Lo (1991), which in the case of one-sided test these values are 1,620 1,747 at the respective threshold of $10 \%$ and $5 \%$.

The results show that only six rounds among the twenty-one exhibit long term dependence: the returns of following market indexes: LQ 45, SSE Composite, Tunindex, EGX, Tadawul and Merval. For the rest of the series, the memory detected from the traditional analysis of $\mathrm{R} / \mathrm{S}$ seems to be short-term memory, this confirms what we have previously mentioned, the statistic R/S is sensitive to the presence of a short-term memory in the return series, thus we can conclude that long memory is a characteristic of efficient markets at the expense of developed one.

The absence of long memory dynamics can be rationalized for developed stock markets on the grounds that they are informationally efficient. Prices tend to reflect all publicly available information and any new one is fully arbitraged away. Thin markets, on the other hand, are characterized by various institutional rigidities that perpetuate informational inefficiency and asymmetry. 
Inappropriate information acquisition and dissemination about firms issuing equities, lack of adequate regulatory environment, especially in relation to property rights and protection of creditors were found to be strongly associated with low levels of financial and stock market development.

In addition, the presence of price manipulations, use of inside information and the inadequacy of important institutional aspects in relation to listing requirements and the absence of specialized brokers, tend to be typical characteristics of thin markets. These characteristics encourage speculative activities and may explain the departure of stock prices in these markets from their fundamentals and their slow adjustment to new information.

\section{b- Study of persistence over periods with different trends}

For the sake of rigor we will try to show in this paragraph if there is some connection between detection of long-term persistence and the market trend, for this reason we divided the study period in each index bullish and bearish periods, the results are summarized in the table in appendix 3.

The table shows that the ownership of long-term dependence on market index returns tend to be associated with stock market indicating an upward trend, a phenomenon that suggests that long memory may be linked to particular characteristics of the environment in which each stock markets works.

\section{Conclusion}

A market is informationally efficient if it is impossible to predict future returns from past returns since all information, known or anticipated, is already incorporated in the price. So, it is impossible to make abnormal profits by speculating on the difference between the observed market price and its fundamental value. But this definition of efficiency is challenged by the presence of long memory in that persistence is characterized by an autocorrelation function which decays slowly when the delay increases and this leads to the existence of a gap sustainable between market price and its fundamental value.

The procedure of the heuristic R / S amended, which provides us with statistical V shows that only six rounds among the twenty-one exhibit long term dependence: the following returns of market indexes LQ 45, SSE Composite, Tunindex, EGX, Tadawul and Merval therefore we can infer a violation of the assumption of weak form of efficiency in these markets. Whereas for the other series there was evidence of a short memory that is to say, a presence of short-term autocorrelation, more it was observed that the characteristic of long memory seems to be closely linked to countries whose level of development is relatively low and markets that the trend is up.

The persistence completely destroys the hypothesis of market efficiency since it signals a time required for the integration of information in the price. A persistent market would be a market where information fits very slowly. In a market antipersistant integration of information is also very slow, but mostly because of overreactions that are corrected, over time. We are far from ideal market defined by the proponents of the rationality of investors. 


\section{Macrothink Institute $^{\text {TM }}$}

However the analysis conducted here and the methodology allowed for determining the Hurst exponent suspect bias caused for example by short term dependence. This study should be replicated using LO statistics to cancel this bias.

\section{References}

Andrews, Donald W K. (1991). Heteroskedasticity and Autocorrelation Consistent Covariance Matrix Estimation. Econometrica, Econometric Society, 59(3).

Backus, D.K., \& S.E. Zin. (1993). long-memory inflation uncertainty: Evidence from the term structure of interest rates. Journal of Money, Credit and Banking, 25, 681-700. http://dx.doi.org/10.2307/2077735

Baillie, R.T. (1996). Long memory processes and fractional integration in econometrics. Journal of Econometrics 73, 5-59. http://dx.doi.org/10.1016/0304-4076(95)01732-1

Bernstein, Peter L. (1999). A New Look at the Efficient Market Hypothesis. The Journal of Portfolio Management, 25(2), 1-2. http://dx.doi.org/10.3905/jpm.1999.390965

Bollerslev T., \& Mikkelsen I.O (1996). Modeling and pricing long memory in stock market volatility. Journal of Derivatives, 4(3), 63-71.

David G. McMillan, \& Pako Thupayagale. (2009). The efficiency of African equity markets. Studies in Economics and Finance, 26(4), 275-292. http://dx.doi.org/10.1108/10867370910995726

Davidson, J., \& Terasvirta, T.T. (Eds.) (2002). Long Memory and Nonllinear Time Series. Journal of Econometrics, 110(2), 105-437. http://dx.doi.org/10.1016/S0304-4076(02)00088-X

Diebold, F.X., \& G.D. Rudebusch. (1989). long-memory and persistence in aggregate output. $\begin{array}{lllll}\text { Journal of } & \text { Monetary } & \text { Economics, } & \text { 24, }\end{array}$ http://dx.doi.org/10.1016/0304-3932(89)90003-2

Diebold, F.X., \& G.D. Rudebusch. (1991). Forecasting output with the Composite Leading Index: A real time analysis. Journal of Monetary Economics, 24, 189-209. http://dx.doi.org/10.1016/0304-3932(89)90003-2

Doukhan, P., Oppenheim, G., \& Taqqu, M.S. (2003). Theory and Applications of Long-range Dependence. Birkhauser, Berlin.

Dufrénot G., \& Mignon V. (2002). Recent Developments in Nonlinear Cointegration With Applications to Macroeconomics and Finance. Kluwer Academic Publishers, 299 pages. http://dx.doi.org/10.1007/978-1-4757-3615-1

Frieder, L., \& Subrhmanyam, A. (2005). Brand Perceptions and the Market for Common Stock. Journal of Financial and Quantitative Analysis, 40(1), 57-86. http://dx.doi.org/10.1017/S0022109000001745 


\section{Macrothink}

Geweke J., \& Porter-Hudak S. (1990). The estimation and application of long-memory time series models. Theory Related Fields, 86, 87-104.

Geweke J., \& S. Porter-Hudak. (1983). The estimation and application of long memory time series models. Journal of Time Series Analysis, 4, 221-238. http://dx.doi.org/10.1111/j.1467-9892.1983.tb00371.x

Hosking, J.R.M. (1981). Fractional differencing. Biometrika, 68, 165-176. http://dx.doi.org/10.1093/biomet/68.1.165

Hsieh, D. (1991). Chaos and Nonlinear Dynamics: Applications to Financial Markets. Journal of Finance, 46, 1839-1877. http://dx.doi.org/10.1111/j.1540-6261.1991.tb04646.x

Hurst, H.E. (1951). Long-term storage capacity of reservoirs. Transactions of the American Society of Civil Engineers, 116, 770-799.

Jacobsen, B. (1996). Long term dependence in stock returns. Journal of Empirical Finance, 33, 93-417. http://dx.doi.org/10.1016/S0927-5398(96)00009-6

Lo, A.W. (1991). Long-term memory in stock market prices. Econometrica, 59, 1279-1313. http://dx.doi.org/10.2307/2938368

LO, Andrew W. (2008). Efficient Markets Hypothesis. The New Palgrave Dictionary of Economics. Second ed. London: Palgrave Macmillan.

Malkiel, Burton G. (2003). The Efficient Market Hypothesis and Its Critics. The Journal of Economic Perspectives, 17(1), 59-82. http://dx.doi.org/10.1257/089533003321164958

Malkiel, Burton G. (2005). Reflections on the Efficient Market Hypothesis: 30 Years Later. The Financial Review, 40(1), 1-9. http://dx.doi.org/10.1111/j.0732-8516.2005.00090.x

MANDELBROT, B.B. (1972). Statistical methodology for non-periodic cycles: from the covariance to R/S analysis. Annals of Economic and Social Measurement, 1, 259-290.

Mandelbrot, B.B., \& Wallis, J. (1968). N. Joseph and operational hydrology. Water Resources Research, 4, 909-918. http://dx.doi.org/10.1029/WR004i005p00909

McLeod, A.I., \& K.W. Hipel (1978). Preservation of the rescaled adjusted range, I: A reassessment of the Hurst phenomenon. Water Resources Research, 14, 491-508. http://dx.doi.org/10.1029/WR014i003p00491

Mignon V. (1998). Marchés financiers et modélisation des rentabilités boursières. Economica, Paris.

Mignon, V. (1997). Long-term memory and chaos. Springer Verlag.

NATH, Golaka C. (2001). Long Memory and Indian Stock Market-An Empirical Evidence. UTIICM Conference Paper. 


\section{Macrothink}

Newey, Whitney K; West, \& Kenneth D (1987). A Simple, Positive Semi-definite, Heteroskedasticity and Autocorrelation Consistent Covariance Matrix. Econometrica, 55(3), 703-708. http://dx.doi.org/10.2307/1913610

Olsen (1998). Behavioral finance and Ib implications for stock, price Volatility. Financial Analysts Journal, 54(02), 10-8. http://dx.doi.org/10.2469/faj.v54.n2.2161

Opong, K.K., Mulholland, G., Fox, A.F., \& Farahmand, K. (1999). The Behavior of Some UK Equity Indicies: An Application of Hurst and BDS Tests. Journal of Empirical Finance, 6, 267-282. http://dx.doi.org/10.1016/S0927-5398(99)00004-3

Peters, Edgar E. (1994). Fractal Market Analysis: Applying Chaos Theory to Investment and Economics. New York: John Wiley \& Sons.

Robinson, P. M., \& M. Henry. (2003). Higher Order Kernel Semiparametric M-estimation of Long Memory. Journal of Econometrics, Volume, 114(1), 1-27. http://dx.doi.org/10.1016/S0304-4076(02)00208-7

Robinson, P.M. (1994). Time series with strong dependence. Advances in Econometrics, 1, Sixth World Congress. http://dx.doi.org/10.1017/CCOL0521444594.002

Scheinkman, J., \& Xiong, W. (2003). Overconfidence and Speculative Bubles. Princeton University.

Shea, G.S. (1991). Uncertainty and implied variance bounds in long-memory models of the interest rate term structure. Empirical Economics, 16, 287-312. http://dx.doi.org/10.1007/BF01206277

Timotej Jagric, Boris Podobnik, \& Marko Kolanovic. (2005). Does the Efficient Market Hypothesis Hold?: Evidence from Six Transition Economies. Eastern European Economics, 43(4), 79-103.

Willinger, Taqqu,M., \& Teverovsky, V. (1999). Stock market prices and long range dependence. Finance and Stochastics, 3, 1-13. http://dx.doi.org/10.1007/s007800050049 
Appendix 1. Calculation of statistics

\begin{tabular}{|c|c|c|c|c|c|c|c|c|c|}
\hline & Sk & $\mathbf{K u}$ & JB & $\begin{array}{c}\text { augmented } \\
\text { ADF test }\end{array}$ & $\begin{array}{c}\text { Phillips } \\
\text { Perron } \\
\text { test }\end{array}$ & KPSS test & White test & BP & $\begin{array}{c}\text { Corrected } \\
\text { BP }\end{array}$ \\
\hline CAC 40 & 0.394002 & 2.103227 & 165.3771 & -0.883028 & -1.909149 & 0.933378 & 49.64519 & 93.505 & 0.924 \\
\hline SP500 & -0.094044 & 2.309546 & 58.9987 & -1.125635 & -1.97652 & 0.517874 & 162.6621 & 90.096 & 0.904 \\
\hline FTSE100 & 0.069159 & 2.023732 & 112.5762 & -0.581993 & -2.05624 & 1.245823 & 70.64741 & 91.362 & 0.918 \\
\hline MIBTEL & -0.609381 & 2.57556 & 161.14 & -1.028095 & -1.138692 & 0.389724 & 30.61981 & 52.727 & 0.696 \\
\hline S\$P/TSX & 0.255913 & 1.921781 & 162.0988 & -0.712938 & -1.145514 & 3.655343 & 46.71394 & 77.706 & 0.825 \\
\hline NIKKEI225 & 0.555232 & 2.239857 & 203.5808 & -0.221833 & -2.067614 & 0.674326 & 68.02753 & 88.534 & 0.903 \\
\hline DAX & 0.741152 & 2.450057 & 276.5251 & 2.412442 & 1.439008 & 5.471842 & 1.356799 & 70.828 & 0.747 \\
\hline LQ-45 & 1.173229 & 3.646805 & 708.4385 & -0.756041 & -1.563469 & 1.588478 & 8.895463 & 88.982 & 0.865 \\
\hline ISE-100 & 1.173229 & 3.646805 & 708.4385 & -0.756041 & -1.563469 & 1.588478 & 8.895463 & 88.982 & 0.865 \\
\hline BOVESPA & 1.173229 & 3.646805 & 708.4385 & -0.756041 & -1.563469 & 1.588478 & 8.895463 & 88.982 & 0.865 \\
\hline IPC & 0.373146 & 1.59505 & 290.8353 & 1.813961 & 0.519614 & 6.02364 & 7.629063 & 88.926 & 0.91 \\
\hline SSE Composite & 1.566885 & 5.228426 & 1739.25 & -0.675308 & -1.296607 & 2.399185 & 51.48741 & 53.727 & 0.541 \\
\hline NIFTY & 0.35994 & 1.632654 & 272.4151 & 0.471062 & -0.775398 & 5.014026 & 15.36807 & 83.986 & 0.894 \\
\hline MICEX & 0.35994 & 1.632654 & 272.4151 & 0.471062 & -0.775398 & 5.014026 & $3.856: 88$ & 89.902 & 0.925 \\
\hline TUNINDEX & 0.35994 & 1.632654 & 272.4151 & 0.471062 & -0.775398 & 5.014026 & 10.30639 & 91.008 & 0.917 \\
\hline EGX 30 & 0.309711 & 1.752994 & 218.1046 & 0.08139 & -0.05649 & 5.461516 & 14.9595 & 88.037 & 0.913 \\
\hline KOSPI & -0.23072 & 1.819784 & 192.0314 & 0.38657 & -1.347061 & 4.593266 & 25.16599 & 94.214 & 0.918 \\
\hline FTSE JSE & 0.741152 & 2.450057 & 276.5251 & 2.412442 & 1.439008 & 5.471842 & 15.733 & 95.749 & 0.928 \\
\hline TADAWUL & 0.275576 & 2.151303 & 115.6757 & 2.408518 & -1.415932 & 5.36574 & 6.084847 & 67.116 & 0.715 \\
\hline MERVAL & 0.701316 & 2.462213 & 264.9612 & -0.424588 & 1.064622 & 3.782724 & 87.923398 & 96.715 & 0.95 \\
\hline SP/ASX50 & 0.275576 & 2.151303 & 115.6757 & 2.408518 & -1.412094 & 5.36574 & 6.084847 & 67.116 & 0.715 \\
\hline
\end{tabular}


Appendix 2. BDS test 2012, Vol. 4, No. 2

\begin{tabular}{|c|ccccc|}
\cline { 2 - 6 } \multicolumn{1}{c|}{} & $\mathbf{m}=\mathbf{2}$ & $\mathbf{m}=\mathbf{3}$ & $\mathbf{m}=\mathbf{4}$ & $\mathbf{m}=\mathbf{5}$ & $\mathbf{m = 6}$ \\
\hline CAC 40 & 0.199275 & 0.339375 & 0.437110 & 0.504935 & 0.551655 \\
\hline SP500 & 0.194668 & 0.331305 & 0.426298 & 0.491704 & 0.536258 \\
\hline FTSE100 & 0.199484 & 0.339653 & 0.437364 & 0.505101 & 0.551680 \\
\hline MIBTEL & 0.200159 & 0.340773 & 0.439051 & 0.507463 & 0.554796 \\
\hline S\$P/TSX & 0.199943 & 0.340754 & 0.439325 & 0.508052 & 0.555781 \\
\hline NIKKEI225 & 0.199491 & 0.339799 & 0.437821 & 0.505855 & 0.552810 \\
\hline DAX & 0.199230 & 0.338960 & 0.436134 & 0.503358 & 0.549520 \\
\hline LQ-45 & 0.204226 & 0.347457 & 0.447681 & 0.517762 & 0.566679 \\
\hline ISE-100 & 0.200639 & 0.341248 & 0.439326 & 0.507518 & 0.554635 \\
\hline BOVESPA & 0.201991 & 0.343534 & 0.442407 & 0.511357 & 0.559235 \\
\hline IPC & 0.205602 & 0.349702 & 0.450469 & 0.520933 & 0.570155 \\
\hline SSE ComPosite & 0.201384 & 0.342999 & 0.441986 & 0.510891 & 0.558640 \\
\hline NIFTY & 0.204708 & 0.347868 & 0.447624 & 0.516912 & 0.565031 \\
\hline MICEX & 0.202683 & 0.345584 & 0.446030 & 0.516349 & 0.565413 \\
\hline TUNINDEX & 0.206120 & 0.350577 & 0.451900 & 0.522912 & 0.572689 \\
\hline EGX 30 & 0.202295 & 0.344421 & 0.444074 & 0.513492 & 0.561626 \\
\hline KOSPI & 0.201379 & 0.343122 & 0.442448 & 0.511916 & 0.560366 \\
\hline FTSE JSE & 0.202732 & 0.344788 & 0.444075 & 0.513062 & 0.560907 \\
\hline MADAWUL & 0.206939 & 0.350932 & 0.450755 & 0.519802 & 0.567414 \\
\hline SP/ASX50 & 0.198840 & 0.339053 & 0.436813 & 0.504648 & 0.551390 \\
\hline
\end{tabular}


Calculation of the R/S statistic and Hurst exponent

\begin{tabular}{|c|ccc|cccc|}
\cline { 2 - 8 } & \multicolumn{4}{c|}{ The analysis R / } & \multicolumn{4}{c|}{ The analysis R / S modified } \\
\cline { 2 - 8 } & Hurst & $\mathbf{d}$ & $\mathbf{C}_{\mathbf{m}}$ & Hurst & $\mathbf{d}$ & $\mathbf{C}_{\mathbf{m}}$ & $\mathbf{V}$ \\
\hline CAC 40 & $\mathbf{0 . 8 3 5 3 0 8}$ & 0.335308 & 0.591752 & 0.441819 & -0.058181 & -0.077489 & 0.63 \\
\hline SP500 & $\mathbf{0 . 5 4 3 7 4 7}$ & 0.043747 & 0.062523 & $\mathbf{0 . 5 3 7 8 6 7}$ & 0.037867 & 0.053898 & 1.35 \\
\hline FTSE100 & $\mathbf{0 . 5 3 5 2 2 0}$ & 0.035220 & 0.050037 & $\mathbf{0 . 5 4 1 4 9 0}$ & 0.041490 & 0.059203 & 1.39 \\
\hline MIBTEL & $\mathbf{0 . 5 9 8 8 9 1}$ & 0.098891 & 0.146933 & $\mathbf{0 . 5 6 1 4 4 8}$ & 0.061448 & 0.088919 & 1.61 \\
\hline S\$P/TSX & $\mathbf{0 . 5 7 7 0 3 3}$ & 0.077033 & 0.112701 & $\mathbf{0 . 5 5 5 3 8 8}$ & 0.055388 & 0.079809 & 1.55 \\
\hline NIKKEI225 & $\mathbf{0 . 5 5 3 4 1 6}$ & 0.053416 & 0.076861 & $\mathbf{0 . 5 3 4 1 7 8}$ & 0.034178 & 0.048521 & 1.31 \\
\hline DAX & $\mathbf{0 . 5 5 4 6 9 1}$ & 0.054691 & 0.078767 & $\mathbf{0 . 5 5 5 2 1 2}$ & 0.055212 & 0.079545 & 1.55 \\
\hline ISE-100 & $\mathbf{0 . 5 4 7 9 5 2}$ & 0.047952 & 0.068735 & $\mathbf{0 . 5 2 8 8 3 0}$ & 0.028830 & 0.040776 & 1.27 \\
\hline LQ-45 & $\mathbf{0 . 6 0 4 0 8 2}$ & 0.104082 & 0.155217 & $\mathbf{0 . 5 7 8 0 2 4}$ & 0.078024 & 0.1142311 & $\mathbf{1 . 8 5}$ \\
\hline BOVESPA & $\mathbf{0 . 5 7 5 0 2 4}$ & 0.075024 & 0.109607 & $\mathbf{0 . 5 3 0 5 5 7}$ & 0.030557 & 0.043271 & 1.28 \\
\hline IPC & $\mathbf{0 . 5 6 1 2 1 3}$ & 0.061213 & 0.088564 & $\mathbf{0 . 5 4 6 9 0 1}$ & 0.046901 & 0.067179 & 1.45 \\
\hline SSE ComPosite & $\mathbf{0 . 6 1 9 4 0 8}$ & 0.119408 & 0.180024 & $\mathbf{0 . 5 6 6 0 3 8}$ & 0.066038 & 0.095869 & $\mathbf{1 . 6 9}$ \\
\hline NIFTY & $\mathbf{0 . 5 8 2 1 1 9}$ & 0.082119 & 0.120574 & $\mathbf{0 . 5 5 3 1 0 5}$ & 0.053105 & 0.076397 & 1.52 \\
\hline MICEX & $\mathbf{0 . 5 7 3 4 3 8}$ & 0.073438 & 0.107169 & $\mathbf{0 . 5 3 6 9 7 5}$ & 0.036975 & 0.052595 & 1.34 \\
\hline TUNINDEX & $\mathbf{0 . 6 5 3 7 1 0}$ & 0.153710 & 0.237492 & $\mathbf{0 . 6 0 0 1 8 0}$ & 0.100180 & 0.148984 & $\mathbf{2 . 2 1}$ \\
\hline EGX 30 & $\mathbf{0 . 5 9 0 3 5 5}$ & 0.090355 & 0.133441 & $\mathbf{0 . 5 7 2 7 3 2}$ & 0.072732 & 0.106086 & $\mathbf{1 . 7 7}$ \\
\hline KOSPI & $\mathbf{0 . 5 6 4 9 6 4}$ & 0.064964 & 0.094239 & $\mathbf{0 . 5 2 8 2 2 5}$ & 0.028225 & 0.039904 & 1.25 \\
\hline FTSE JSE & $\mathbf{0 . 5 4 5 9 0 4}$ & 0.045904 & 0.065704 & $\mathbf{0 . 5 1 0 5 5 9}$ & 0.010559 & 0.014745 & 1.09 \\
\hline TADAWUL & $\mathbf{0 . 6 4 8 5 9 0}$ & 0.148590 & 0.228740 & $\mathbf{0 . 5 7 4 7 3 9}$ & 0.074739 & 0.109168 & $\mathbf{1 . 8 2}$ \\
\hline MERVAL & $\mathbf{0 . 6 0 0 4 2 4}$ & 0.100424 & 0.149375 & $\mathbf{0 . 5 6 4 8 7 0}$ & 0.064870 & 0.094096 & $\mathbf{1 . 6 7}$ \\
\hline SP/ASX50 & $\mathbf{0 . 5 3 8 8 3 2}$ & 0.038832 & 0.055308 & $\mathbf{0 . 5 4 2 3 5 5}$ & 0.042355 & 0.060474 & 1.40 \\
\hline & & & & & & & \\
\hline
\end{tabular}

\section{Appendix 3. Calculation of the Hurst exponent on returns}

The analysis $\mathrm{R}$ / $\mathrm{S} \quad$ The analysis $\mathrm{R}$ / $\mathrm{S}$ modlified

\begin{tabular}{|c|c|c|c|c|c|c|c|c|}
\hline & Period & Hurst & d & $\mathrm{C}_{\mathrm{m}}$ & Hurst & d & $\mathrm{C}_{\mathrm{m}}$ & $\mathbf{V}$ \\
\hline \multirow{4}{*}{ DAX } & 1 & 0.566 & 0.066 & 0.096 & 0.563 & 0.063 & 0.092 & 1.75 \\
\hline & 2 & 0.563 & 0.063 & 0.092 & 0.516 & 0.016 & 0.022 & 1.13 \\
\hline & 3 & 0.578 & 0.078 & 0.114 & 0.521 & 0.021 & 0.030 & 1.21 \\
\hline & 4 & 0.571 & 0.071 & 0.103 & 0.457 & -0.043 & -0.058 & 0.7 \\
\hline \multirow{5}{*}{ S\$P/TSX } & 1 & 0.587 & 0.087 & 0.128 & 0.548 & 0.048 & 0.070 & 1.55 \\
\hline & 2 & 0.573 & 0.073 & 0.107 & 0.517 & 0.017 & 0.024 & 1.17 \\
\hline & 3 & 0.560 & 0.060 & 0.086 & 0.509 & 0.009 & 0.012 & 1.08 \\
\hline & 4 & 0.591 & 0.091 & 0.134 & 0.519 & 0.019 & 0.027 & 1.2 \\
\hline & 5 & 0.573 & 0.073 & 0.106 & 0.563 & 0.063 & 0.091 & 1.75 \\
\hline \multirow{2}{*}{ MIBTEL } & 1 & 0.564 & 0.064 & 0.092 & 0.514 & 0.014 & 0.020 & 1.15 \\
\hline & 2 & 0.571 & 0.071 & 0.103 & 0.451 & -0.049 & -0.066 & 0.6 \\
\hline
\end{tabular}




\begin{tabular}{|c|c|c|c|c|c|c|c|c|}
\hline & 3 & 0.575 & 0.075 & 0.109 & 0.766 & 0.266 & 0.445 & 1.2 \\
\hline & 4 & 0.571 & 0.071 & 0.103 & 0.523 & 0.023 & 0.032 & 1.27 \\
\hline \multirow{4}{*}{ SP500 } & 1 & 0.565 & 0.065 & 0.094 & 0.451 & -0.049 & -0.066 & 0.7 \\
\hline & 2 & 0.560 & 0.060 & 0.086 & 0.397 & -0.103 & -0.133 & 0.5 \\
\hline & 3 & 0.575 & 0.075 & 0.110 & 0.419 & -0.081 & -0.107 & 0.55 \\
\hline & 4 & 0.573 & 0.073 & 0.106 & 0.572 & 0.072 & 0.105 & 1.6 \\
\hline \multirow{4}{*}{ FTSE100 } & 1 & 0.565 & 0.065 & 0.094 & 0.421 & -0.079 & -0.103 & 0.5 \\
\hline & 2 & 0.561 & 0.061 & 0.089 & 0.592 & 0.592 & 1.272 & 1.25 \\
\hline & 3 & 0.575 & 0.075 & 0.110 & 0.539 & 0.539 & 1.112 & 1.15 \\
\hline & 4 & 0.573 & 0.073 & 0.106 & 0.604 & 0.604 & 1.309 & 1.22 \\
\hline \multirow{4}{*}{ CAC 40} & 1 & 0.568 & 0.068 & 0.099 & 0.441 & -0.059 & -0.079 & 0.6 \\
\hline & 2 & 0.563 & 0.063 & 0.091 & 0.467 & -0.033 & -0.045 & 0.77 \\
\hline & 3 & 0.572 & 0.072 & 0.104 & 0.437 & -0.063 & -0.083 & 0.58 \\
\hline & 4 & 0.575 & 0.075 & 0.109 & 0.446 & -0.054 & -0.072 & 0.65 \\
\hline \multirow{4}{*}{ NIKKEI225 } & 1 & 0.565 & 0.065 & 0.094 & 0.510 & 0.010 & 0.014 & 1.1 \\
\hline & 2 & 0.561 & 0.061 & 0.089 & 0.514 & 0.014 & 0.019 & 1.13 \\
\hline & 3 & 0.577 & 0.077 & 0.113 & 0.501 & 0.001 & 0.001 & 1.01 \\
\hline & 4 & 0.571 & 0.071 & 0.103 & 0.572 & 0.072 & 0.105 & 1.9 \\
\hline \multirow{5}{*}{ FTSE JSE } & 1 & 0.557 & 0.057 & 0.082 & 0.367 & -0.133 & -0.168 & 0.5 \\
\hline & 2 & 0.582 & 0.082 & 0.120 & 0.532 & 0.032 & 0.045 & 1.25 \\
\hline & 3 & 0.593 & 0.093 & 0.138 & 0.522 & 0.022 & 0.031 & 1.15 \\
\hline & 4 & 0.565 & 0.065 & 0.094 & 0.531 & 0.031 & 0.044 & 1.22 \\
\hline & 5 & 0.566 & 0.066 & 0.096 & 0.599 & 0.099 & 0.147 & 1.9 \\
\hline \multirow{3}{*}{ Nerval } & 1 & 0.559 & 0.059 & 0.085 & 0.542 & 0.042 & 0.059 & 1.3 \\
\hline & 2 & 0.584 & 0.084 & 0.123 & 0.539 & 0.039 & 0.055 & 1.35 \\
\hline & 3 & 0.570 & 0.070 & 0.101 & 0.523 & 0.023 & 0.032 & 1.17 \\
\hline \multirow{3}{*}{ KOSPI } & 1 & 0.559 & 0.059 & 0.085 & 0.368 & -0.132 & -0.167 & 0.4 \\
\hline & 2 & 0.580 & 0.080 & 0.117 & 0.533 & 0.033 & 0.047 & 1.29 \\
\hline & 3 & 0.573 & 0.073 & 0.107 & 0.622 & 0.122 & 0.184 & 2.3 \\
\hline \multirow{2}{*}{ TUNINDEX } & 1 & 0.565 & 0.065 & 0.094 & 0.544 & 0.044 & 0.063 & 1.37 \\
\hline & 2 & 0.559 & 0.059 & 0.085 & 0.615 & 0.115 & 0.172 & 2.22 \\
\hline \multirow{5}{*}{ TADAWUL } & 1 & 0.558 & 0.058 & 0.084 & 0.525 & 0.025 & 0.035 & 1.19 \\
\hline & 2 & 0.578 & 0.078 & 0.114 & 0.527 & 0.027 & 0.038 & 1.29 \\
\hline & 3 & 0.587 & 0.087 & 0.128 & 0.549 & 0.049 & 0.071 & 1.52 \\
\hline & 4 & 0.583 & 0.083 & 0.123 & 0.510 & 0.010 & 0.014 & 1.09 \\
\hline & 5 & 0.569 & 0.069 & 0.101 & 0.696 & 0.196 & 0.312 & 5.1 \\
\hline \multirow{3}{*}{ SP/ASX50 } & 1 & 0.558 & 0.058 & 0.084 & 0.456 & -0.044 & -0.060 & 0.7 \\
\hline & 2 & 0.582 & 0.082 & 0.120 & 0.530 & 0.030 & 0.042 & 1.3 \\
\hline & 3 & 0.575 & 0.075 & 0.109 & 0.522 & 0.022 & 0.031 & 1.2 \\
\hline \multirow{4}{*}{ EGX 30} & 1 & 0.566 & 0.066 & 0.096 & 0.528 & 0.028 & 0.039 & 1.23 \\
\hline & 2 & 0.565 & 0.065 & 0.094 & 0.526 & 0.026 & 0.036 & 1.18 \\
\hline & 3 & 0.609 & 0.109 & 0.162 & 0.581 & 0.081 & 0.119 & 2.07 \\
\hline & 4 & 0.571 & 0.071 & 0.103 & 0.393 & -0.107 & -0.138 & 0.4 \\
\hline
\end{tabular}


